\title{
Transcriptional Silencing of Geminiviral Promoter-Driven Transgenes Following Homologous Virus Infection
}

\author{
Mark Seemanpillai, ${ }^{1}$ Ian Dry, ${ }^{2}$ John Randles, ${ }^{1}$ and Ali Rezaian ${ }^{2}$ \\ ${ }^{1}$ The University of Adelaide, Department of Applied and Molecular Ecology, Urrbrae, SA 5064, Australia; ${ }^{2}$ CSIRO Plant \\ Industry, Horticulture Unit, PO BOX 350, Glen Osmond SA 5064, Australia
}

Submitted 9 September 2002. Accepted 30 December 2002.

\begin{abstract}
Promoters isolated from the Tomato leaf curl virus (TLCV) drive both constitutive and tissue-specific expression in transgenic tobacco. Following systemic TLCV infection of plants stably expressing TLCV promoter:GUS transgenes, transgene expression driven by all six TLCV promoters was silenced. Silencing in the TLCV coat protein promoter:GUS plants (V2:GUS $\Delta C$ ) was characterized in more detail. Transgene silencing observed in leaf, stem, and preanthesis floral tissue occurred with the continued replication of TLCV in host tissues. Infection of the V2:GUS $\Delta C$ plants with heterologous geminiviruses did not result in transgene silencing, indicating that silencing was specifically associated with TLCV infection. Nuclear run-on assays indicated that silencing was due to the abolition of transcription from the V2:GUS $\Delta \mathrm{C}$ transgene. Bisulfite sequencing showed that silencing was associated with cytosine hypermethylation of the TLCV-derived promoter sequences of the V2:GUS $\Delta C$ transgene. Progeny derived from V2:GUS $\Delta$ C plants silenced by TLCV infection were analyzed. Transgene expression was silenced in progeny seedlings but was partially reactivated in the majority of plants by 75 days postgermination. Progeny seedlings treated with the nonmethylatable cytosine analog 5-azacytidine or the histone deacetylase inhibitor sodium butyrate exhibited partial reactivation of expression. This is the first report of the hypermethylation of a virus-derived transgene associated with a DNA virus infection.
\end{abstract}

Additional keywords: transcriptional gene silencing.

Previous studies have demonstrated that foreign genes expressed in plant tissues under the control of a virus-derived promoter may be silenced following infection by a virus carrying the same promoter sequence. Transgene silencing associated with infection by the DNA virus Cauliflower mosaic virus (CaMV) was observed in Brassica species that carried transgenes using the CaMV 35S promoter to drive expression (Al-Kaff et al. 1998, 2000). In these studies, when transgene homology to CaMV sequence was limited to the transgene promoter, silencing was due to the cessation of transcription. The downregulation of transgene expression as a response of plants to virus infection has significant implications for the development of modern strategies of plant virus control. This was demonstrated by the loss of herbicide resistance in a commercial oilseed rape variety carrying a herbicide-resistance gene under the control of the $35 \mathrm{~S}$ promoter. Loss of resistance was associated with infection by CaMV, a virus commonly found throughout the world (Al-Kaff et al. 2000).

Corresponding author: A. Rezaian; E-mail: ali.rezaian@csiro.au.
Transcriptional silencing of plant transgenes also is associated with infections by RNA viruses. Nicotiana species carrying $35 \mathrm{~S}$ promoter:green fluorescent protein (GFP) transgenes were silenced for transgene expression following infection by recombinant forms of either Potato virus X (PVX) or Tobacco rattle virus (TRV) carrying an insert of the CaMV 35S promoter (Jones et al. 1999, 2001). PVX and TRV, which have genomes and replication intermediates composed of RNA, were associated with transgene silencing due to transcriptional inactivation. As the $35 \mathrm{~S}$ promoter insert carried by either PVX or TRV is unlikely to be active as a promoter, it is not promoter functionality but sequence homology between the virus and the transgene that underlies virus-induced transgene silencing. Unlike the DNA virus CaMV (Al-Kaff et al. 2000), silencing involving PVX or TRV was associated with hypermethylation of cytosines within the virus-derived promoter sequences of the plant transgenes (Jones et al. 1999, 2001). Further studies have revealed that progeny derived from plants silenced for 35S promoter:GFP transgene expression by infection with TRV carrying a $35 \mathrm{~S}$ promoter copy can inherit the silenced state of the transgene in the absence of the recombinant TRV (Jones et al. 2001).

Geminiviruses are plant pathogens and have a circular monopartite or bipartite single-stranded DNA genome that is replicated in the nuclei of host cells, possibly by a combination of rolling circle and recombination-dependent replication mechanisms (Jeske et al. 2001). During replication, the singlestranded DNA is converted by host factors to a double-stranded DNA intermediate, which is the template for transcription of viral open reading frames (ORF) and the further synthesis of single-stranded viral DNA. Transcription of geminivirus genes is most likely carried out by the host RNA polymerase II (Hanley-Bowdoin et al. 1999).

The regulation of gene expression in the monopartite geminivirus Tomato leaf curl virus (TLCV) was investigated recently by Dry and associates (2000). All six putative promoters of the virion- and complementary-sense TLCV genes were fused with $\beta$-glucuronidase (GUS). Tobacco was stably transformed with the reporter transgenes, and the activity and spatial expression pattern of each transgene was examined. Here, we report the silencing of expression from tobacco transgenes containing the GUS gene, under the control of promoter sequences derived from the TLCV, following infection by TLCV.

\section{RESULTS}

GUS activity in TLCV promoter:GUS plants is abolished following TLCV infection.

To characterize TLCV promoters in planta, transgenic tobacco lines were generated, carrying integrated TLCV promoter:GUS constructs described previously (Dry et al. 2000). 
The six TLCV promoter:GUS transgenes (Fig. 1) directed expression of GUS in tobacco tissue in patterns described either as constitutive (C1:GUS, C4:GUS, and V2:GUS $\Delta \mathrm{C}$ ), restricted to vascular tissues (C2:GUS and C3:GUS), or reduced expression in vascular tissues (V1:GUS $\Delta \mathrm{C}$ ), as shown in Figure 2A.
TLCV promoter:GUS or CaMV 35S:GUS tobacco plants were agroinoculated with an infectious TLCV construct and were assayed for systemic infection and GUS activity. GUS activity in infected leaf tissue of TLCV promoter:GUS plants was reduced to levels below visual detection by 50 days post-

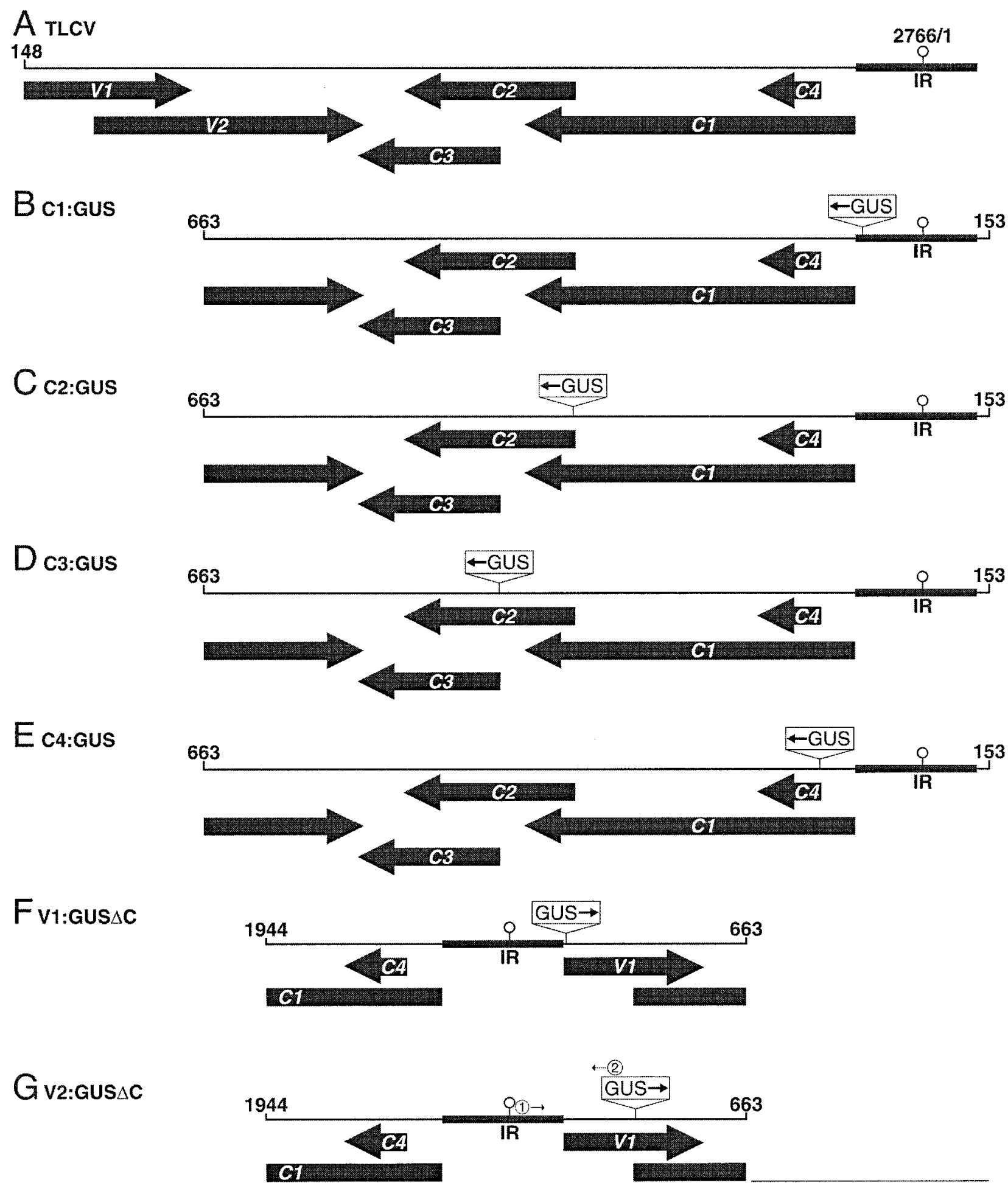

Fig. 1. Schematic presentation of Tomato leaf curl virus (TLCV) promoter:GUS fusion constructs. A, TLCV genome organization. The linearized, doublestranded, replicative form of the genome is represented by a thin line. The intergenic region (IR) containing the origin of replication, including the conserved geminiviral stem-loop motif, is shown as a thick line. Arrows denote the four complementary-sense (C1, C2, C3, and C4) and two virion-sense (V1, and V2) viral open reading frames. B, through G, Promoter:GUS fusion constructs. Open box (GUS) represents a 2.1-kb fragment containing a GUSNOS terminator cassette (not shown to scale). G, Circled numbers (1 and 2) and small arrows above the V2:GUS $\Delta \mathrm{C}$ construct denote the position of the oligonucleotide primers used for bisulfite sequencing of the V2:GUS $\Delta C$ transgene. TLCV forward primer (1); GUS reverse primer (2). 
infection (dpi), while GUS activity in the control CaMV 35S:GUS plants remained unchanged by systemic TLCV infection (Fig. 2A). Silencing of GUS activity was observed in each TLCV promoter:GUS tobacco line and occurred in every plant in which systemic TLCV infection was established (data not shown). Systemic infection of TLCV promoter:GUS plants abolished GUS activity in all tissues examined, including mature leaf, stem, and preanthesis flowers (data not shown). In leaves of infected plants, silencing of GUS activity was initiated in the vascular tissue collateral with the midrib and progressed via vascular tissue into mesophyll tissue towards the leaf margins, until GUS activity in the entire leaf was silenced (Fig. 2B).

Following TLCV inoculation, the progression of symptoms in the TLCV promoter:GUS plants was indistinguishable from those observed in infected CaMV 35S:GUS and nontransgenic tobacco plants (data not shown). In TLCV promoter:GUS plants, TLCV accumulated to titres comparable to that in CaMV 35S:GUS plants at 50 dpi (Fig. 2C), indicating that the presence of the TLCV-derived transgenes in host plants did not prevent the replication and spread of TLCV DNA.

To assess whether the method of TLCV infection used in these experiments to infect transgenic plants, i.e., agroinoculation, was important for the silencing of GUS activity, TLCV promoter:GUS plants were grafted with field-infected tomato (Lycopersicon esculentum) carrying TLCV. GUS activity was also abolished in these plants following systemic TLCV infection (data not shown).

Induction of silencing of GUS is limited to TLCV and a closely-related strain. Plants containing the GUS gene driven by the V2 coat protein promoter (V2:GUS $\Delta \mathrm{C}$ ) were selected for further experiments because of their high level constitutive GUS expression (Fig. 2A). V2:GUS $\Delta$ C plants were infected with a range of related geminiviruses to ascertain whether silencing of the transgenes was TLCV-specific or a general host response to geminiviral infection. Multiple V2:GUS $\Delta \mathrm{C}$ plants were each agroinoculated with either African cassava mosaic virus (ACMV), Tomato yellow leaf curl virus-Sr (TYLCV-Sr) (Dry et al. 1997), or Tomato leaf curl virus-Au strain D1 (TLCV-D1) (Behjatnia et al. 1996) and were assayed for systemic viral infection and GUS expression at $50 \mathrm{dpi}$.

Plants infected with TLCV-D1, a strain of TLCV with $84 \%$ nucleotide identity to the wild-type virus across the intergenic region and 5' end of the C1 ORF (i.e., TLCV nucleotide positions 2,354 to 149) (Behjatnia et al. 1996), resulted in systemic silencing of GUS expression by 50 dpi (Table 1). Infection of the V2:GUS $\triangle \mathrm{C}$ plants by ACMV or TYLCV-Sr failed to induce silencing of GUS expression from the V2:GUS $\Delta \mathrm{C}$ transgene by $50 \mathrm{dpi}$.

\section{Transcription of GUS in V2:GUS $\Delta C$ plants is abolished following TLCV infection.}

GUS transcripts were not detected in infected V2:GUS $\Delta C$ tissue using reverse-transcription-polymerase chain reaction (PCR) (data not shown), indicating that silencing occurred at either the transcriptional or posttranscriptional level. To ascertain whether silencing occurred at the transcriptional level, the level of transcription from the V2:GUS $\Delta \mathrm{C}$ transgene was compared between noninfected and infected V2:GUS $\Delta \mathrm{C}$ plants by nuclear run-on assay. Expanding leaves from five noninfected or infected V2:GUS $\Delta \mathrm{C}$ plants were pooled and intact nuclei isolated. The nuclei were incubated with $\left[\alpha-{ }^{32} \mathrm{P}\right] \mathrm{UTP}$ under
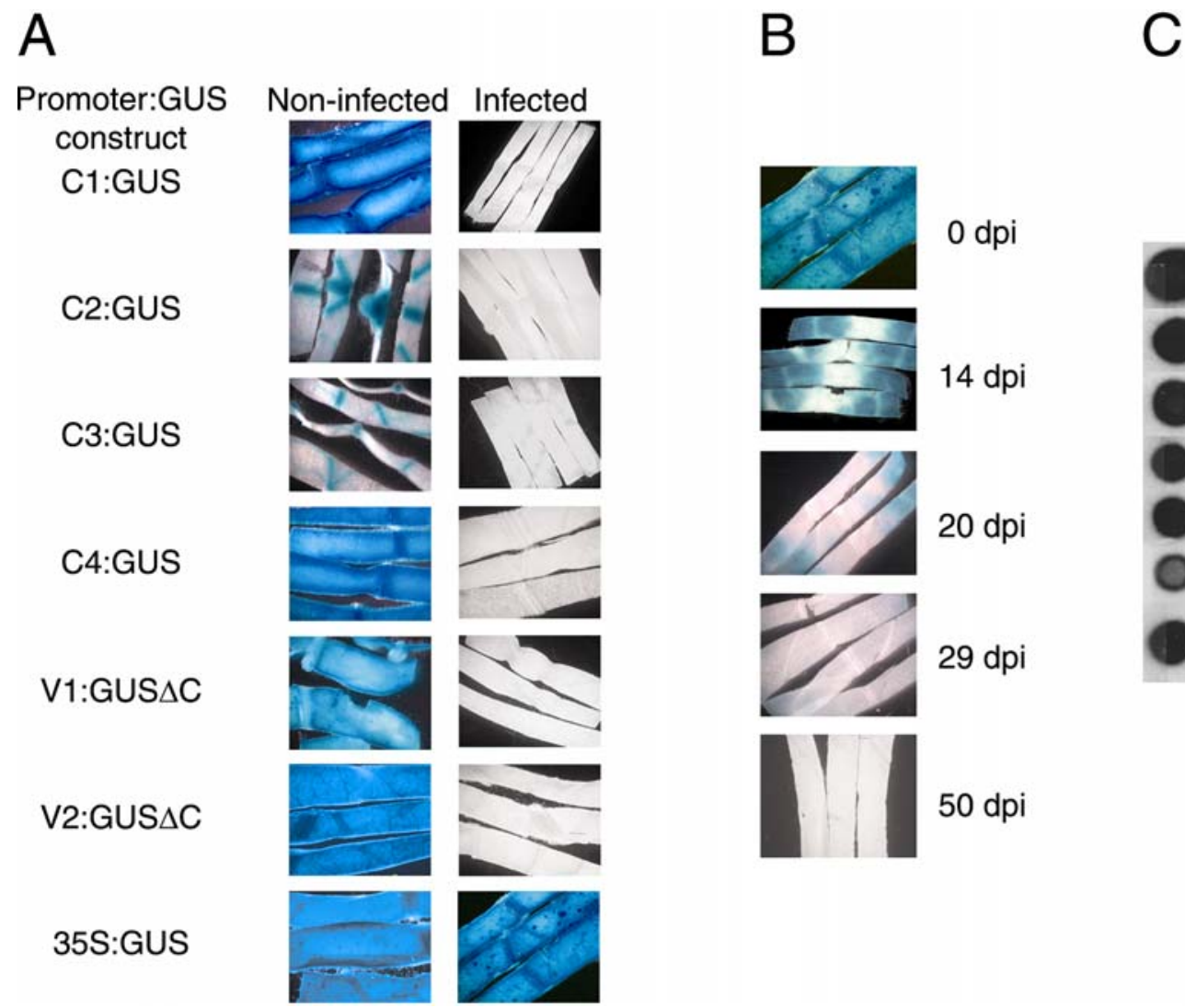

Promoter:GUS
construct
C1:GUS
C2:GUS
C3:GUS
V1:GUS
V2:GUS $\Delta \mathrm{C}$
35S:GUS
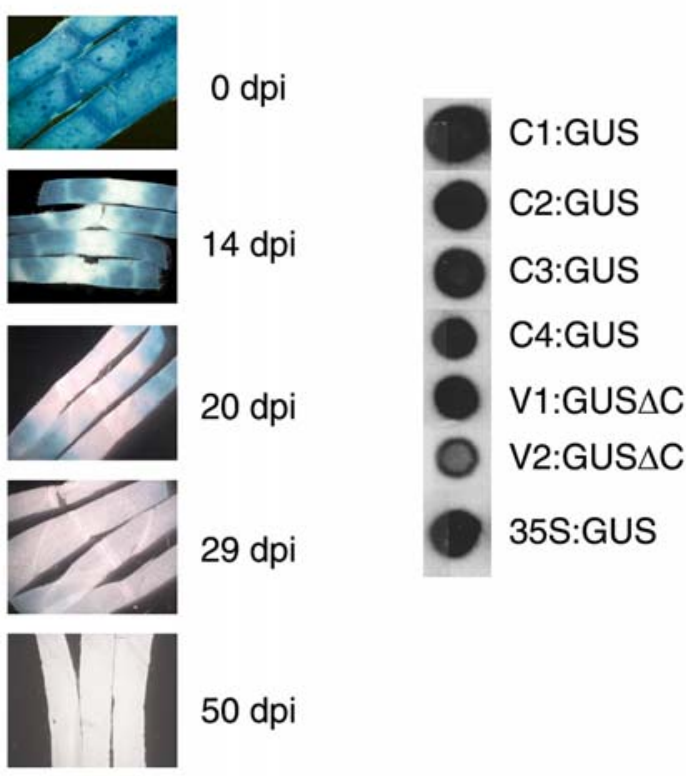

Fig. 2. Tomato leaf curl virus (TLCV) infection silences GUS activity. A, Sections of expanding leaves of TLCV:promoter GUS plants before and after TLCV infection were assayed for GUS activity by histochemical analysis. Sections from a CaMV 35S promoter:GUS plant are shown for comparison. Leaf sections were obtained at 50 days postinoculation (dpi). B, Pattern of GUS activity in V2:GUS $\Delta C$ leaf sections during course of TLCV infection. C, Accumulation of TLCV DNA in TLCV promoter:GUS plants was determined by dot-blot hybridization at 50 dpi. Dot-blot of a CaMV $35 \mathrm{~S}$ promoter:GUS plant infected with TLCV (50 dpi) is shown as a control. 
conditions favorable for the elongation of nascent RNAs. Total RNA from the nuclei was extracted, purified, and used to probe PCR-generated 1.8-kb GUS DNA or $0.3-\mathrm{kb}$ fragments of Rubisco DNA slot-blotted on to nylon membrane.

GUS run-on transcripts were detected in noninfected V2:GUS $\Delta$ C nuclei by hybridization to bound GUS DNA (Fig. 3 , top left band). However, a complete reduction in GUS runon transcripts was observed in nuclei isolated from TLCVinfected V2:GUS $\Delta \mathrm{C}$ plants (Fig. 3). The inability to detect GUS transcripts in infected tissue was unlikely to be a result of lower total RNA levels in this sample, because hybridization to Rubisco was higher using the probe from infected rather than uninfected nuclei (Fig. 3, bottom two bands). Thus, the silencing of expression from the V2:GUS $\Delta \mathrm{C}$ transgene following TLCV infection was due to the abolition of GUS transcription.

\section{TLCV infection correlates}

with hypermethylation of the V2:GUS $\Delta$ C transgene.

We determined the extent of methylation of the TLCVderived promoter region within the transgene in TLCV-infected plants. It was not possible to undertake the typical analysis of DNA methylation patterns by methylation-sensitive enzyme digestion, due to the presence of TLCV replicative form dsDNA in infected plants with homology to the transgene promoter. We therefore utilized bisulfite modification of DNA followed by sequencing, whereby the unmethylated cytosines of bisulfite-treated pooled V2:GUS $\Delta \mathrm{C}$ genomic leaf DNA were converted to uracil. Methylated cytosines are protected from modification; thus, cloning and sequencing the bisulfite-treated DNA detected the methylation status of each cytosine. By specifically amplifying DNA from the coding-strand of the promoter-ORF junction of the V2:GUS $\Delta \mathrm{C}$ transgene, false amplification from viral dsDNA was prevented. The complete modification of unmethylated cytosines to uracil in bisulfite-modified genomic DNA samples was verified by amplification and sequencing of the hypermethylated 5S rDNA sequence. Using previously described primer sequences for bisulfite-modified tobacco $5 \mathrm{~S}$ rDNA, cytosine methylation rates in noninfected plants $(48 \%)$ and infected plants (52\%) were comparable to the published average rate of methylation of 53\% for the top strand of the tobacco 5S rDNA sequence (Fulnecek et al. 1998). A PCR product of $430 \mathrm{bp}$, consisting of $275 \mathrm{bp}$ of TLCV-derived sequence and 155 bp of GUS ORF, was amplified from bisulfite-modified V2:GUS $\Delta \mathrm{C}$ genomic DNA (Figure $1 \mathrm{G}$ shows positions of oligonucleotide primers used) and cloned, and six individual clones were sequenced. By sequencing six clones from modified genomic DNA from either noninfected or TLCV-infected V2:GUS $\Delta$ C plants, a total of 468 cytosine residues in the V2:GUS $\Delta C$ transgene were analyzed, of which 300 residues were in TLCV-derived promoter sequences.

Table 1. Silencing of GUS activity is virus specific ${ }^{\mathrm{a}}$

\begin{tabular}{lcccc}
\hline & & \multicolumn{2}{c}{ GUS activity (DPI) } \\
\cline { 4 - 5 } Virus & \% Identity & & 0 days & 50 days \\
\hline A. tumefaciens pBIN19 & - & + & + \\
Tomato leaf curl virus & 100 & + & - \\
Tomato leaf curl virus strain D1 & 84 & + & - \\
African cassava mosaic virus & 55 & + & + \\
Tomato yellow leaf curl virus $\mathrm{Sr}$ & 54 & + & + \\
\hline
\end{tabular}

${ }^{a}$ Multiple V2:GUS $\triangle C$ plants were infected by agroinoculation with various geminiviruses (three replicates) and were assayed for GUS activity by histochemical staining. Plants were assayed for systemic virus infection by dot-blot hybridization at 50 days postinoculation (dpi). Agrobacterium strains carrying an empty pBIN19 plasmid were used as a negative control

${ }^{\mathrm{b}}$ Percent nucleotide identity to the intergenic region and 5 ' end of the $\mathrm{C} 1$ open reading frame of the wild-type TLCV sequence.
A significant increase was observed in the cytosine methylation of TLCV-derived sequences of the V2:GUS $\Delta \mathrm{C}$ transgene in TLCV-infected plants compared with noninfected plants (Fig. 4). On average in noninfected plants, $30 \%$ of cytosine residues were methylated, while the average methylation rate in TLCV-infected plants increased to $69 \%$. Methylated cytosines can be classified according to adjacent nucleotide sequence; cytosines exist in either $\mathrm{CpG}$ motifs, $\mathrm{CpNpG}$ motifs, or in asymmetric motifs $(\mathrm{CpNpO}$, where $\mathrm{N}$ and $\mathrm{O}$ are not $\mathrm{G})$. Of all cytosines methylated in noninfected plants, $67 \%$ of methylated cytosines were in $\mathrm{CpG}$ motifs, $23 \%$ were in CpNpG motifs, and $10 \%$ in asymmetric motifs. Of all cytosines methylated in infected plants, $41 \%$ of methylated cytosines were in $\mathrm{CpG}$ motifs, $20 \%$ were in $\mathrm{CpNpG}$ motifs, and $39 \%$ in asymmetric motifs. Thus, TLCV infection correlated with a change in the distribution of cytosine methylation in the TLCV-derived V2:GUS $\Delta \mathrm{C}$ sequences, from methylation predominantly of $\mathrm{CpG}$ motifs to more evenly distributed in both symmetric and asymmetric motifs.

Cytosine methylation can also be classified as the proportion of cytosines in each motif that are methylated. In the TLCVderived sequences of the V2:GUS $\Delta \mathrm{C}$ transgene in noninfected plants, $68 \%$ of $\mathrm{CpG}$ motifs, $17 \%$ of $\mathrm{CpNpG}$ motifs, and $14 \%$ of cytosines in asymmetric motifs were methylated. Following TLCV infection of the plants, methylation of the same sequences increased to $91 \%(\mathrm{CpG}), 80 \%(\mathrm{CpNpG})$, and $53 \%$ (asymmetric). The clones generated from bisulfite-modified DNA from both noninfected and TLCV-infected plants displayed varying degrees of methylation in the TLCV-derived transgene sequences. Rates of methylation in clones from noninfected plant DNA ranged from 8 to $37 \%$, while rates in clones from TLCV-infected plant DNA ranged from 58 to $80 \%$, suggesting that hypermethylation of the V2:GUS $\Delta \mathrm{C}$ transgene occurred in most, if not all, leaf cells from plants infected with TLCV.

Compared with the methylation patterns observed in TLCVderived sequences of the $\mathrm{V} 2: \mathrm{GUS} \Delta \mathrm{C}$ transgene, the average rate of methylation in the GUS coding sequence was lower in both noninfected plants (17\%) and TLCV-infected plants $(0.6 \%)$. Methylation of only one cytosine (in an asymmetric motif) was detected in six clones from TLCV-infected plants, indicating the almost total abolition of methylation in the GUS sequences screened. Thus, TLCV infection of V2:GUS $\triangle \mathrm{C}$ plants correlated with a small but significant demethylation of the $5^{\prime}$ region of the GUS ORF of the V2:GUS $\Delta \mathrm{C}$ transgene and significant hypermethylation of the 3 '-region of the TLCVderived sequences.

\section{TLCV-induced silencing of GUS expression is meiotically heritable and reversible in the absence of TLCV.}

To better understand the mechanism or mechanisms mediating TLCV-induced transgene silencing, we investigated whether the silenced state of V2:GUS $\Delta \mathrm{C}$ transgene expression in TLCV-infected plants was heritable. Expression from the V2:GUS $\Delta C$ transgene in second generation $T_{2}$ plants was examined as shown in Figure 5. Four independent $T_{1}$ lines were used to generate $T_{2}$ progeny (four plants per line). Two plants of each line were infected with TLCV, resulting in silencing of GUS expression. The silenced plants were allowed to self-pollinate, and the seeds were collected. These seeds were then germinated in vitro on kanamycin, along with seeds collected from uninfected $\mathrm{T}_{1}$ plants, and the $\mathrm{T}_{2}$ plants were assayed for GUS activity.

Initially, $\mathrm{T}_{2}$ seedlings were tested for GUS activity by histochemical assay of stems with attached leaves. Ten seedlings from either noninfected or TLCV-infected parent plants from 
each independent V2:GUS $\Delta \mathrm{C}$ line were assayed at 10 days postgermination $(\mathrm{dpg})$. $\mathrm{T}_{2}$ seedlings from noninfected parents of each independent line showed normal patterns of GUS expression (data not shown). However, GUS activity could not be detected in $\mathrm{T}_{2}$ seedlings from TLCV-infected parents from any of the independent V2:GUS $\Delta \mathrm{C}$ lines.

To further characterize the TLCV-mediated reduction in GUS activity in $\mathrm{T}_{2}$ seedlings, one line of V2:GUS $\Delta \mathrm{C}$ was chosen, and $\mathrm{T}_{2}$ seedlings were tested by fluorometric GUS assay. Seedlings were pooled and quantitatively assayed for GUS expression at $10 \mathrm{dpg}$. Progeny from the noninfected parent demonstrated an average GUS activity of 244 pmol MU $\mathrm{min}^{-1} \mathrm{mg}$ total protein $^{-1}$, while progeny from the TLCV-infected parent showed a marked reduction in GUS activity to near baseline levels observed in wild-type tobacco (Table 2). TLCV is not seed transmissible (Francki et al. 1985), yet the transcriptionally silenced state of the V2:GUS $\Delta \mathrm{C}$ transgene was inherited by progeny plants in the absence of the virus. This suggested that host mechanisms were silencing transcription from the V2:GUS $\triangle \mathrm{C}$ transgene in the presence of TLCV and that this mechanism or mechanisms were capable of maintaining transcriptional gene silencing (TGS) through meiosis.

Heritable changes in gene expression often are attributed to epigenetic regulatory mechanisms, such as DNA cytosine methylation (Finnegan and Kovac 2000) and histone deacetylation (Jenuwein and Allis 2001; Lusser et al. 2001). To test this, inhibitors of epigenetic mechanisms were included in the germination media of $\mathrm{T}_{2}$ seedlings. 5-Azacytidine is a cytosine analog that incorporates into DNA during replication or repair and prevents methylation by inhibiting DNA methyltransferase (Kumpatla et al. 1997), thus disrupting inherited patterns of DNA methylation in new cells. As inhibitors of histone deacetylases (HDAC), trichostatin A (TSA) and sodium butyrate (SB) have been shown to reactivate silenced transgenes in mammalian cells (Pikaart et al. 1998) and to alleviate nucleosomal dominance in Brassica hybrids (Chen and Pikaard 1997).

Table 2 shows that 5 -azacytidine treatment reactivated GUS activity in $\mathrm{T}_{2}$ seedlings from the TLCV-infected parent to $15 \pm$ 2 pmol MU $\min ^{-1} \mathrm{mg}$ total protein ${ }^{-1}$ (Table 2). However, this represents only a marginal increase in the level of GUS activity compared with the activity of $244 \pm 30$ pmol MU min ${ }^{-1} \mathrm{mg}$ total protein ${ }^{-1}$ observed in the control $(\mathrm{N}-1)$ progeny population. TSA treatment during germination had no apparent effect on GUS activity; however, application of SB increased activity to $38 \pm 4$ pmol MU $\min ^{-1} \mathrm{mg}$ total protein ${ }^{-1}$.

To confirm these findings, the same experiments were performed on $\mathrm{T}_{2} \mathrm{C}$ 1:GUS seedlings from either a noninfected or a TLCV-infected parent. The C1:GUS transgene, based on the fusion of the GUS ORF with the 5' untranslated region of the TLCV C1 transcript (Fig. 1), directs constitutive GUS expression in tobacco (Fig. 2A). $\mathrm{T}_{2}$ seedlings from a noninfected C1:GUS plant demonstrated a GUS activity of $1390 \pm 65$ pmol MU $\min ^{-1} \mathrm{mg}$ total protein ${ }^{-1}$, while GUS activity in progeny from the TLCV-infected parent was $65 \pm 9$ pmol MU min $^{-1} \mathrm{mg}$ total protein ${ }^{-1}$ (Table 2). Although TLCV reduced GUS activity in $\mathrm{T}_{1} \mathrm{C} 1$ :GUS plants to below visual detection, GUS activity at $10 \mathrm{dpg}$ in $\mathrm{T}_{2}$ seedlings from a TLCV-infected parent remained visible and was instead down-regulated. This is in contrast to $\mathrm{T}_{2}$ V2:GUS $\triangle \mathrm{C}$ seedlings from a TLCV-infected parent at 10 $\mathrm{dpg}$, in which transgene expression remained essentially silenced. Inclusion of 5-azacytidine in the germination media of $\mathrm{T}_{2}$ seedlings increased GUS activity by $19 \%$, while treatment with SB resulted in an increase of approximately sixfold. TSA treatment appeared to have no effect on GUS activity.

$\mathrm{T}_{2}$ seedlings of the V2:GUS $\Delta \mathrm{C}$ line that were tested by quantitative GUS assay were transferred to soil and were main- tained in a glasshouse. Ten plants from the noninfected parent and 20 plants from the TLCV-infected parent were tested at 75 dpg by histochemical GUS assay. All of the $\mathrm{T}_{2}$ plants from the noninfected parent showed strong constitutive GUS activity. Approximately $75 \%$ of $T_{2}$ plants from the TLCV-infected parent demonstrated patchy or constitutive GUS activity, which was weaker than that seen in plants from the noninfected parent (data not shown). All $\mathrm{T}_{2}$ plants were then inoculated with TLCV and were assayed for TLCV infection and GUS activity. All plants were susceptible to TLCV, resulting in systemic infection and normal symptom development. Plants positive for GUS activity at $75 \mathrm{dpg}$ that were inoculated with TLCV were all resilenced by $50 \mathrm{dpi}$ (data not shown).

\section{DISCUSSION}

This paper describes the transcriptional silencing of a tobacco transgene containing promoter sequences derived from the DNA geminivirus TLCV. Silencing of the transgene occurred following systemic infection of the tobacco plants by TLCV (Fig. 2) and was associated with hypermethylation of the TLCV-derived promoter transgene sequences (Fig. 4). Progeny derived from tobacco silenced for transgene activity by TLCV infection also were initially silenced for transgene expression. Previous work has shown that silencing of plant transgenes in response to infection by viruses sharing promoter homology (virus-induced transcriptional gene silencing or VITGS) can be triggered by DNA (Al-Kaff et al. 2000) and RNA viruses (Jones et al. 2001) and results in heritable transgene silencing, due to transcriptional inactivation accompanied, in the case of RNA viruses, by hypermethylation of the transgene promoter. Based on these observations, the phenomenon of TLCV-induced silencing of the TLCV promoter:GUS plant transgenes represents another example of VITGS. To date, this is the first report of VITGS associated with a geminivirus infection.

Analysis of plants undergoing TLCV-induced VITGS by nuclear run-on analysis of the V2:GUS $\Delta \mathrm{C}$ transgene demonstrated that silencing was due to inactivation of the TLCVderived promoter sequence. Consistent with previous observations of VITGS (Jones et al. 1999, 2001), TLCV infection is associated with hypermethylation of the TLCV-derived sequences of the V2:GUS $\Delta \mathrm{C}$ transgene. The analysis of transgene promoter methylation following PVX infection by Southern blotting indicated that VITGS resulted in hypermethylation of both symmetric and asymmetric cytosines (Jones et al. 1999). Hypermethylation of an asymmetric cytosine associated with TRV-induced TGS (Jones et al. 2001) was an order of magnitude higher than TLCV-induced average hypermethylation of asymmetric cytosines. This observation may be ex-

\section{Non-infected Infected}

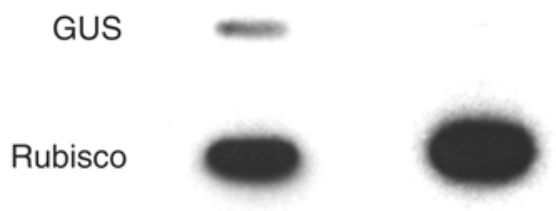

Fig. 3. Tomato leaf curl virus (TLCV) infection is associated with a lack of GUS transcription. Nuclear run-on analysis of nuclei isolated from noninfected or TLCV-infected V2:GUS $\triangle \mathrm{C}$ leaves was performed at 50 days postinfection. Radiolabeled total RNA purified from $3.5 \times 10^{6}$ nuclei was used to probe a slot-blot containing $5 \mu \mathrm{g}$ of full-length GUS and $0.5 \mu \mathrm{g}$ of a 300-bp fragment of Rubisco DNA. 
plained by the susceptibility of TRV to PTGS (Ratcliff et al. 1999) and the subsequent production of small TRV 35S promoter short interfering RNAs (siRNAs), which are efficient inducers of methylation of homologous nuclear sequences (Mette et al. 2000). Hamilton and associates (2002) have recently postulated that the 25-nt class of siRNAs are closely involved in the methylation of plant genomic DNA sequences. It therefore seems possible that siRNAs of viral sequence produced during infection direct the sequence-specific methylation of genomic viral sequences observed during VITGS. Experiments are in progress to determine the potential role of TLCV siRNAs during VITGS.

Currently, there is limited information available on bisulfite sequencing of host DNA methylation following plant pathogen-homologous transgene interactions. Analysis of an integrated satellite of the Cereal yellow dwarf virus (CYDVsat) in tobacco following extrachromosomal replica- tion of the homologous CYDVsat RNA led to transgene hypermethylation, which was mostly restricted to CYDVsatderived sequences (Wang et al. 2001). Following CYDVsat infection, methylation of the transgene cytosines was observed in $85 \%$ of symmetric motifs and in $57 \%$ of asymmetric motifs, a pattern closely mirrored in TLCV-induced transgene hypermethylation. Hypermethylation was strictly limited to homologous TLCV-derived host sequences and was typical of methylation of host sequences previously observed to be associated with RNA viruses.

The silencing, either wholly or partially, of TLCV promoter:GUS transgenes in virus-free progeny plants from parents in which transgene expression was silenced by TLCV infection indicates the involvement of one or more host mechanisms that maintained the repression of transgenes through meiosis. Initially, all V2:GUS $\Delta \mathrm{C} \mathrm{T}_{2}$ progeny were silenced, but transgene activity was partially restored in $75 \%$ of progeny 75

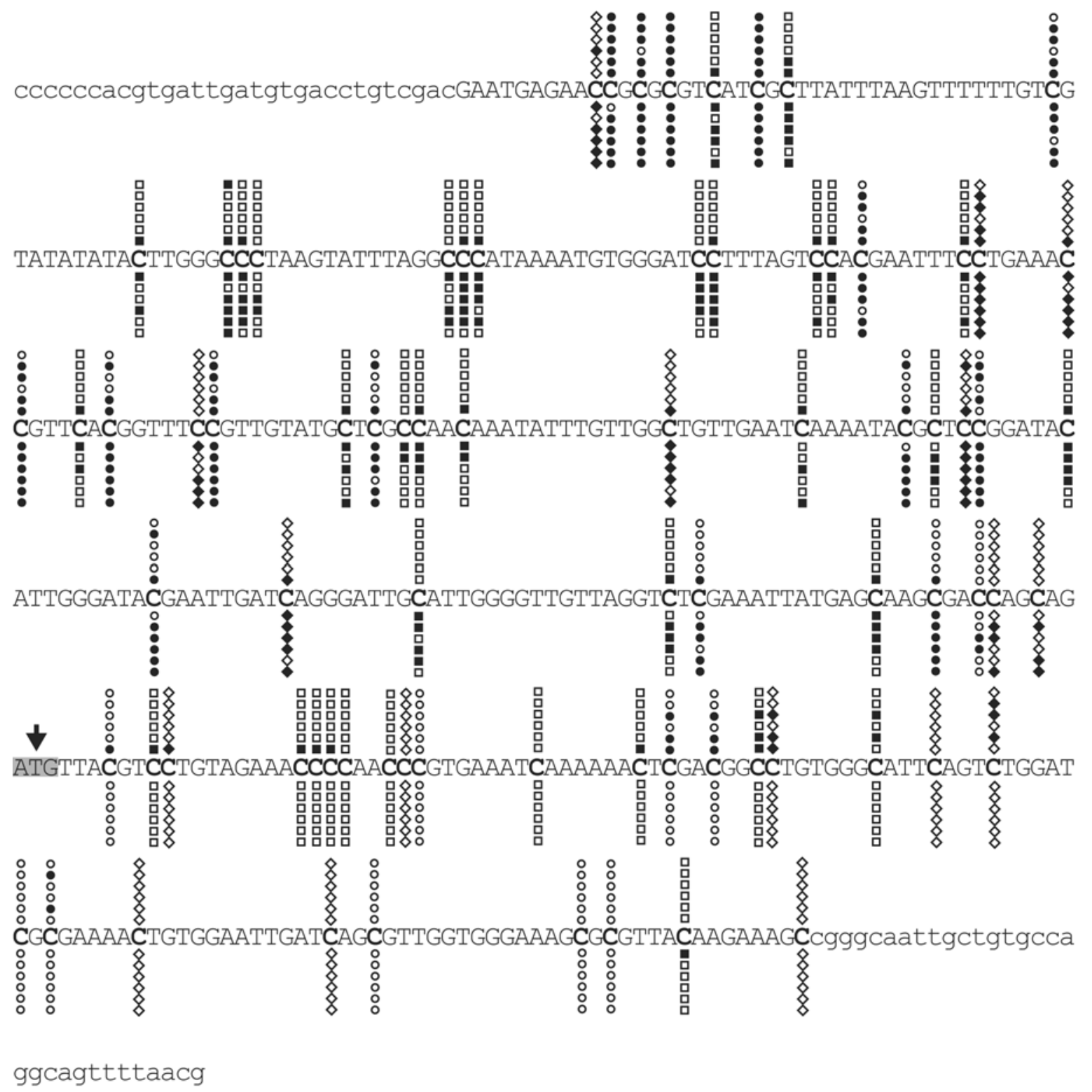

Fig. 4. Cytosine methylation at the promoter:ORF junction of the V2:GUS $\triangle \mathrm{C}$ transgene. Bisulfite modification of genomic DNA extracted from either six noninfected or Tomato leaf curl virus (TLCV)-infected V2:GUS $\triangle \mathrm{C}$ leaves was performed, and a 430-bp polymerase chain reaction (PCR) product amplified from the coding strand of the transgene promoter:ORF junction was cloned and sequenced. The wild-type sequence is shown, and cytosines potentially subject to modification are in bold. Methylated and unchanged cytosines of noninfected and TLCV-infected V2:GUS $\triangle \mathrm{C}$ plants are shown above and below the sequence, respectively. The initiation codon (ATG) of the GUS ORF is shaded grey and is indicated by the arrow ( $\downarrow$ ). PCR primer sequences are in lower case. Cytosines in $\mathrm{CpG}$ motifs are denoted by circles, cytosines in $\mathrm{CpNpG}$ motifs are denoted by diamonds, and asymmetric cytosines by squares. Unfilled symbols represent an unmethylated cytosine residue, and filled circles represent methylated cytosines residues. 
days after germination, a similar proportion of reversion observed in progeny from plants having undergone VITGS due to TRV (Jones et al. 2001). Reactivation of the transgene in $\mathrm{T}_{2}$ V2:GUS $\triangle \mathrm{C}$ progeny indicated that TLCV did not effect silencing of the transgene in the $T_{1}$ parent plant by inducing sequence mutations. The reactivation of expression from the V2:GUS $\triangle \mathrm{C}$ transgene in the absence of TLCV provides an argument for a heritable yet reversible host epigenetic process, such as chromatin modification, as the mechanism mediating TLCV-induced silencing of the homologous TLCV promoter:GUS transgenes.

Previous examples of heritable transcriptional gene silencing point to the importance of DNA methylation in maintaining silencing in progeny (Jones et al. 2001; Matzke and Matzke 1991). Other cases show histone deacetylation, a process often implicated in the maintenance of established chromatin states, as required for the maintenance of gene silencing (Chen and Townes 2000; Lorincz et al. 2001; Pikaart et al. 1998). The application of inhibitors of methylation or histone deacetylation resulted in partial reactivation of expression from the V2:GUS $\Delta \mathrm{C}$ and $\mathrm{C} 1$ :GUS transgenes in $\mathrm{T}_{2}$ seedlings obtained from TLCV-infected parents (Table 2), suggesting a role for these processes in the inheritance of the silenced state of the transgenes.

Interference with established methylation patterns in silenced V2:GUS $\Delta \mathrm{C}$ progeny plants through 5-azacytidine treatment (Table 2) suggested that the inherited silencing was at least partially mediated by the methylation of the TLCV promoter:GUS transgenes acquired in parent plants; a conclusion supporting the finding that a maintenance methyltransferase was required for the inheritance of transgene silencing due to TRV (Jones et al. 2001). Treatment of silenced C1:GUS progeny with 5-azacytidine resulted in a smaller, less significant increase in GUS activity compared with V2:GUS $\Delta \mathrm{C}$ progeny, indicating that the contribution of cytosine methylation toward the inheritance of VITGS may vary between transgenic lines.

Of particular interest is the divergent responses in transgene reactivation observed using the histone deacetylase inhibitors TSA and SB (Table 2). TSA is reported as a specific HDAC inhibitor that can reactivate silenced mammalian transgenes at nanomolar concentrations (Chen et al. 1997). SB produces many reversible changes in cultured mammalian cells, which are proposed to result from changes in chromatin structure and cytoskeleton assembly (Kruh 1982), in addition to histone hyperacetylation. More recent evidence has shown the ability of SB but not of TSA to reactivate expression from a mammalian transgene in which silencing was directed by promoter methylation, prompting the proposal of an alternative silencing mechanism operating simultaneously with histone deacetylation in mediating methylation-directed gene silencing (Benjamin and Jost 2001). The absence of transgene reactivation in $T_{2}$ seedlings from TLCV-infected parents treated with TSA suggests that one or more alternative pathways to histone hypoacetylation may be predominantly responsible for the inherited silencing or downregulation of transgene activity.

It is important to note the continued replication of TLCV following VITGS, as demonstrated by the presence of TLCV DNA and the continued disease symptoms. Apparently, the mechanisms mediating VITGS did not cause concurrent inactivation of the viral promoter within the replicating virus. Geminiviruses, once having gained entrance to the nucleus of host cells, convert their single-stranded DNA genomes to a doublestranded replicative form, which is then assembled into a minichromosome, most likely using host histones (Pilartz and Jeske 1992). Thus at some stages of the geminivirus replicative lifecycle, the viral DNA closely resembles the host genome. It is puzzling, therefore, that TLCV-induced transcriptional gene si- lencing appears to be uni-directional. One explanation may be that only a small number of viral copies are required to silence GUS activity in each infected cell and that these viral copies as well as the transgenes become inactivated. The inactivated transgenes may not be able to interact further with copies of TLCV, leaving the remaining population of viral copies to replicate freely.

We have obtained evidence that a geminivirus, TLCV, is able to induce transcriptional gene silencing of a homologous integrated plant transgene characterized by hypermethylation of the virus-derived integrated sequences. Transcriptional silencing of the virus-derived integrated sequences did not extend to the episomal replicating viral DNA but was inherited in progeny plants. The reactivation of transgene expression in progeny established that inheritance was mediated by one or more host epigenetic processes; our results implicate both cytosine methylation and changes in chromatin configuration as required for the inheritance of virus-induced transcriptional gene silencing.

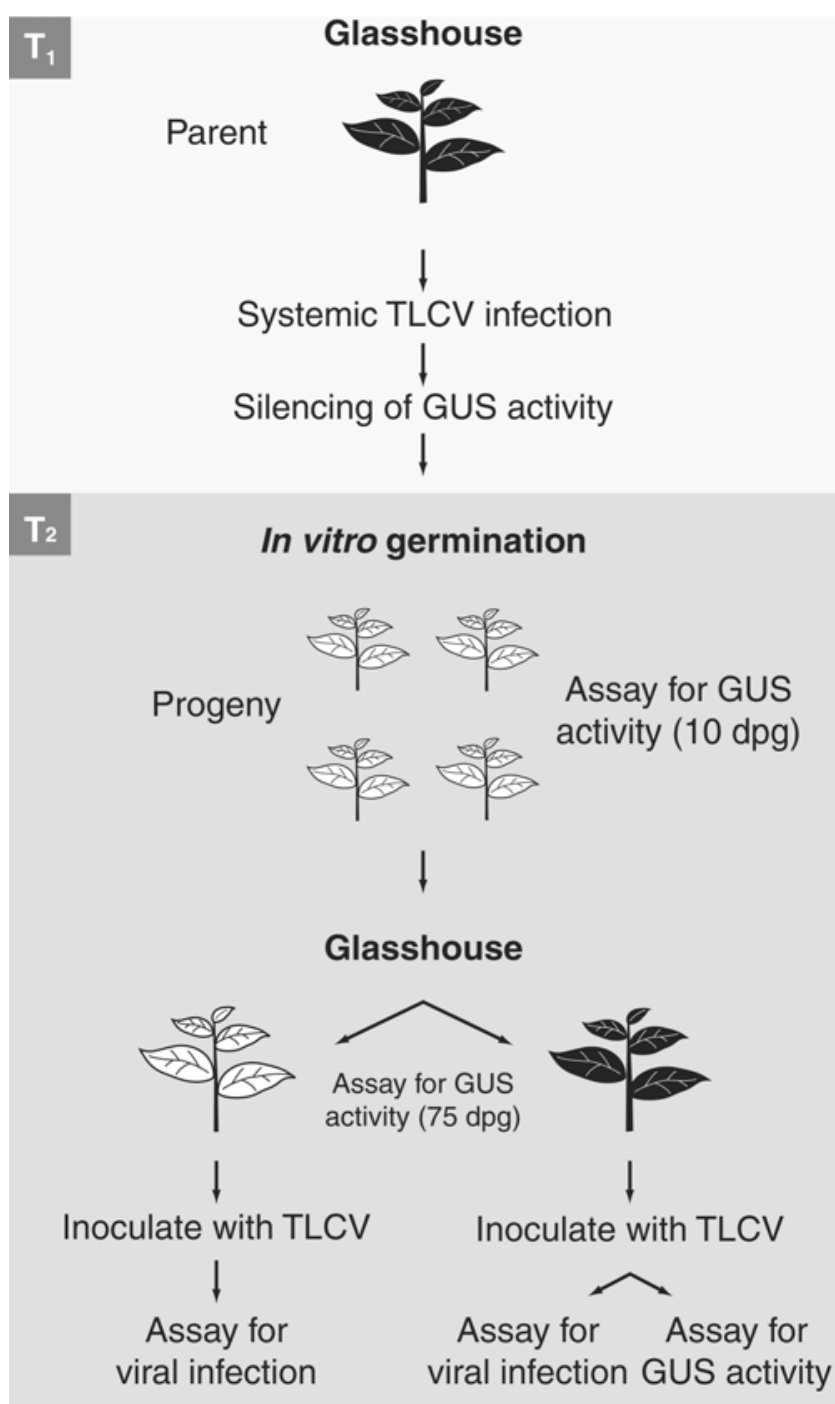

Fig. 5. Analysis of GUS expression in second generation V2:GUS $\Delta C$ plants. The diagram depicts the approach used to analyze transgene expression in progeny $\left(\mathrm{T}_{2}\right)$ plants. Filled plants $=$ positive for $\beta$ glucuronidase (GUS) activity; unfilled plants = negative for GUS activity. Virus infection was established by agroinoculation. GUS activity was assayed by histochemical or quantitative analysis of whole seedlings or leaf sections. Seeds were germinated on kanamycin to select for transgenic seedlings. Plants were assayed for viral infection by dot-blot hybridization. dpg = days postgermination. 


\section{MATERIALS AND METHODS}

\section{Plant lines and growth.}

A series of six transgenic Nicotiana tabacum (cv. Samsun) lines were generated, carrying stably integrated TLCV promoter:GUS transgenes (Dry et al. 2000). These transgenes, with the exception of the C1:GUS construct, were in-frame Nterminal translational fusions of an Escherichia coli uidA-NOS terminator cassette with the viral ORFs and directed expression of a GUS protein with a leader sequence of 1 to 13 amino acids of virus gene product. To construct the C1:GUS transgene, a uidA-NOSter cassette was inserted in the $5^{\prime}$ untranslated region of the C1 ORF $24 \mathrm{bp}$ upstream of the $\mathrm{C} 1$ start codon. Unless stated otherwise, all transgenic tobacco plants used were $T_{1}$ generation.

In vitro germination of tobacco seeds. Tobacco seeds were incubated in $4 \%$ ( $\mathrm{vol} / \mathrm{vol}$ ) hypochlorite for $30 \mathrm{~min}$ and then were washed in sterile water for 2 min five times each. Seeds were germinated on Murashige and Skoog agar containing 3\% (wt/vol) sucrose and $50 \mu \mathrm{g}$ kanamycin per $\mathrm{ml}$ at $23^{\circ} \mathrm{C}$ under a 16-h photoperiod. As required, $75 \mu \mathrm{g}$ 5-azacytdine per $\mathrm{ml}$ (Sigma, St. Louis), $10 \mu \mathrm{M}$ trichostatin A (Sigma), or $10 \mathrm{mM}$ sodium butyrate (Sigma) was added to germination media.

Glasshouse growth conditions. Plants were maintained in glasshouses under quarantine conditions at $25 \pm 3^{\circ} \mathrm{C}$ under natural lighting.

\section{Analysis of GUS activity.}

Histochemical detection of GUS activity was performed (Jefferson et al. 1986) as described by Dry and associates (2000). GUS assays of in vitro germinated seedlings were performed up to $10 \mathrm{dpg}$ without tissue dissection.

Quantitative assay. Seedling leaf and stem tissue was harvested and pooled. The weighed seedlings were ground in liquid nitrogen, were resuspended in 2.5 vol extraction buffer (EB; $50 \mathrm{mM}$ sodium phosphate, $\mathrm{pH}$ 7, $1 \mathrm{mM}$ EDTA, $0.1 \%$ [vol/vol] sarcosyl, $0.1 \%$ [vol/vol] Triton X-100, $0.078 \%$ [vol/vol] $\beta$-mercaptoethanol), and were vortexed for $15 \mathrm{~s}$ before centrifugation at $4^{\circ} \mathrm{C}$ for $15 \mathrm{~min}$ at $25,200 \times g$. The supernatant was frozen in liquid nitrogen and thawed on ice, and 20

Table 2. The silenced state of the V2:GUS $\triangle \mathrm{C}$ transgene is meiotically heritable ${ }^{\mathrm{a}}$

\begin{tabular}{lccc}
\hline Transgene & Parent & Treatment & GUS activity $^{\mathbf{b}}$ \\
\hline V2:GUS $\triangle \mathrm{C}$ & $\mathrm{N}-1^{\mathrm{c}}$ & & $244(30)$ \\
& $\mathrm{S}-1^{\mathrm{d}}$ & & $3(1)$ \\
& $\mathrm{S}-1$ & $\mathrm{AzaC}^{\mathrm{e}}$ & $15(2)$ \\
& $\mathrm{S}-1$ & $\mathrm{TSA}^{\mathrm{f}}$ & $4(1)$ \\
$\mathrm{S}-1$ & $\mathrm{SB}^{\mathrm{g}}$ & $38(4)$ \\
C1:GUS & $\mathrm{N}-1$ & & $1390(65)$ \\
& $\mathrm{S}-1$ & & $65(9)$ \\
& $\mathrm{S}-1$ & $\mathrm{AzaC}$ & $81(8)$ \\
& $\mathrm{S}-1$ & $\mathrm{TSA}$ & $68(5)$ \\
& $\mathrm{S}-1$ & $\mathrm{SB}$ & $462(26)$ \\
\hline
\end{tabular}

${ }^{\mathrm{a}} \mathrm{T}_{2}$ V2:GUS $\triangle \mathrm{C}$ and $\mathrm{C} 1$ :GUS seedlings were germinated in vitro and were tested at 10 days postgermination for GUS activity. Crude protein extracts were tested in duplicate by quantitative fluorometric GUS assay, and total protein concentration was determined. GUS activities were corrected for background (wild-type tobacco) levels. Activities shown are the average of three independent extractions. Standard errors are shown in parentheses. Chemical modifiers of epigenetic regulation were added to the germination media as required.

${ }^{\mathrm{b}}$ In pmol MU $\mathrm{min}^{-1} \mathrm{mg}^{-1}$ total protein.

c $\mathrm{N}-1=$ noninfected and nonsilenced $\mathrm{T}_{1}$ plant.

${ }^{\mathrm{d}} \mathrm{S}-1=\mathrm{TLCV}$-infected and silenced $\mathrm{T}_{1}$ plant.

e $\mathrm{AzaC}=5$-azacytidine

f $\mathrm{TSA}=$ trichostatin $\mathrm{A}$.

${ }^{\mathrm{g}} \mathrm{SB}=$ sodium butyrate. $\mu \mathrm{l}$ of supernatant was added to $430 \mu \mathrm{l}$ of preheated $\left(37^{\circ} \mathrm{C}\right)$ assay buffer (1 mM methylumbelliferyl-beta-D-glucuronic acid [MU], 40\% [vol/vol] methanol, 60\% [vol/vol] EB), vortexed briefly, and then incubated at $37^{\circ} \mathrm{C}$. As required, $100 \mu \mathrm{l}$ aliquots were added to $1,900 \mu \mathrm{l}$ stop buffer $(0.2 \mathrm{M}$ sodium carbonate), and product concentration was measured with a fluorometer (TKO 100; Hoefer Scientific Instruments, San Francisco) by comparison with known concentration standards.

\section{Geminivirus infectivity assays.}

Agroinoculations were performed, as described previously (Dry et al. 1993), with Agrobacterium tumefaciens strain C58 carrying infectious head-to-tail copies of either TLCV, ACMV, or TYLCV genomic (Dry et al. 1997) DNA inserted in pBIN19. pBIN19 vectors carrying TLCV ORF mutants are described in Rigden and associates (1996). Systemic virus infection was determined by DNA dot-blot analysis. Leaf tissue from agroinoculated plants was homogenized in two volumes of $0.5 \mathrm{M} \mathrm{NaOH}$ and was centrifuged at $15,000 \times g$ for $30 \mathrm{~min}$. Supernatant $(4 \mu \mathrm{l})$ was dotted onto Zeta-Probe nylon membrane (Bio-Rad, Hercules, CA, U.S.A.). Membranes were briefly rinsed in chloroform, washed in $2 \times \mathrm{SSC}(1 \times \mathrm{SSC}$ is $0.15 \mathrm{M} \mathrm{NaCl}$ plus $0.015 \mathrm{M}$ sodium citrate), and UV crosslinked (UV Stratalinker 1800; Stratagene, La Jolla, CA, U.S.A.). Membranes were hybridized overnight as described below with random primer-generated radiolabeled TLCV DNA.

\section{Extraction and analysis of RNA.}

Tobacco nucleic acids were extracted as described by Dry and associates (1993), with the following modifications. The midrib was removed from leaf tissue before homogenization, and the resuspended tissue was extracted three times with phenol and then once with chloroform.

\section{Nuclei run-on assays.}

Isolation of leaf nuclei. Tobacco plants were placed in the dark for $24 \mathrm{~h}$ prior to extraction. Small, expanding leaves were harvested, and the midrib was removed to obtain $1 \mathrm{~g}$ of tissue. The tissue was chopped manually on ice for $20 \mathrm{~min}$ in $1 \mathrm{ml}$ of buffer A (0.44 M sucrose, 2.5\% [wt/vol] Ficoll 400, 5.0\% [wt/vol] Dextran T40, $25 \mathrm{mM}$ Tris-HCl, pH 8.5, $10 \mathrm{mM}$ $\mathrm{MgCl}_{2}, 2.5 \%$ [vol/vol] Triton X-100, $10 \mathrm{mM} \beta$-mercaptoethanol, $2 \mathrm{mM}$ spermine). The tissue was diluted with $9 \mathrm{ml}$ of buffer A, was filtered through one layer of cheesecloth and two layers of Miracloth (Calbiochem, San Diego, CA, U.S.A.), and was gently agitated by hand for $30 \mathrm{~s}$. The filtrate was centrifuged at $1,000 \times g$ for $30 \mathrm{~min}$ at $4^{\circ} \mathrm{C}$, and crude nuclear pellets were resuspended in $250 \mu \mathrm{l}$ of buffer B (0.44 M sucrose, $2.5 \%$ [wt/vol] Ficoll 400, 5\% [wt/vol] Dextran T40, 25 mM Tris$\mathrm{HCl}, \mathrm{pH} 8.5,10 \mathrm{mM} \mathrm{MgCl}$, 2.5\% [vol/vol] Triton X-100, 10 $\mathrm{mM} \beta$-mercaptoethanol). The resuspension was loaded onto a $2-\mathrm{ml} 60 \%$ sucrose column (column height $=1.75 \mathrm{~cm}$ ) and was centrifuged at $1,000 \times g$ for $30 \mathrm{~min}$ at $4^{\circ} \mathrm{C}$. Nuclei pellets were resuspended in $250 \mu \mathrm{l}$ of buffer $\mathrm{C}(50 \mathrm{mM}$ Tris- $\mathrm{HCl}, \mathrm{pH} 8.5,5$ $\mathrm{mM} \mathrm{MgCl} 2,10 \mathrm{mM} \beta$-mercaptoethanol, 20\% [vol/vol] glycerol), were snap-frozen in liquid nitrogen, and were stored at $80^{\circ} \mathrm{C}$. Nuclei were enumerated on a haemocytometer under a fluorescence microscope after staining with either 4',6-diamidino-2-phenylindole or SYBR Gold (Molecular Probes, Eugene, OR, U.S.A.).

Nuclear run-on transcription. Nuclei $\left(3.5 \times 10^{6}\right)$ were pelleted at $4^{\circ} \mathrm{C}$ and were resuspended in $225 \mu$ of reaction buffer (50 mM Tris-HCl, pH 7.9, $0.1 \mathrm{mM}$ DTT, $10 \mathrm{mM}$ $\mathrm{MgCl}_{2}, 50 \mathrm{mM}\left(\mathrm{NH}_{4}\right)_{2} \mathrm{SO}_{4}, 125 \mu \mathrm{g} \mathrm{BSA}, 0.2 \mathrm{mM}$ GTP, 0.2 $\mathrm{mM}$ ATP, $0.2 \mathrm{mM}$ CTP, $175 \mathrm{U}$ of the RNase inhibitor SUPERase.In [Ambion, Austin, TX, U.S.A.]). Twenty-five 
microliters $(250 \mu \mathrm{Ci})$ of $\left[\alpha{ }^{32} \mathrm{P}\right] \mathrm{UTP}\left(3000 \mathrm{Ci} \mathrm{mmol}{ }^{-1} ; 37\right.$ $\mathrm{MBq} \mathrm{ml} \mathrm{l}^{-1}$; Perkin-Elmer, Foster City, CA, U.S.A.) was added, and the reactions were incubated at $30^{\circ} \mathrm{C}$ for $2 \mathrm{~h}$. RNase-free DNase (150 U) and $45 \mu \mathrm{l}$ DNase digestion buffer (Promega, Madison, WI, U.S.A.) were added, and reactions were incubated for a further $10 \mathrm{~min}$. Proteinase K $(40 \mu \mathrm{g}), 50$ $\mu \mathrm{g}$ of $E$. coli tRNA, and $50 \mu \mathrm{l}$ of proteinase digestion buffer (100 mM Tris-HCl, $\mathrm{pH} 7.5,50 \mathrm{mM}$ EDTA, 10\% [vol/vol] sodium dodecyl sulfate [SDS]) was added, and the reactions were incubated at room temperature for $25 \mathrm{~min}$. Nucleic acids were purified by phenol extraction and chloroform extraction and were passed through Micro Bio-Spin P30 Tris columns (Bio-Rad), according to the manufacturer's instructions. Eluates were pooled, and 1- $\mu$ l aliquots were counted in a scintillation counter.

Preparation of DNA filters and hybridization. Purified DNA $(0.5$ to $5 \mu \mathrm{g}$ ) was bound to Zeta-Probe GT nylon membranes (Bio-Rad) using a Hoefer PR 648 slot-blot apparatus, according to the manufacturer's instructions (Bio-Rad). Hybridizations were performed in $0.25 \mathrm{M}$ sodium phosphate ( $\mathrm{pH} 7.2$ ) and $7 \%$ (vol/vol) SDS at $65^{\circ} \mathrm{C}$ for $72 \mathrm{~h}$, using all of the radiolabeled RNA. Hybridized filters were washed at $65^{\circ} \mathrm{C}$ in $2 \times \mathrm{SSC}$ and $0.1 \% \mathrm{SDS}$ two times for $5 \mathrm{~min}$, then in $0.1 \times$ SSC and $0.1 \%$ SDS for $20 \mathrm{~min}$, and then were exposed to Kodak Biomax film with an intensifying screen at $-70^{\circ} \mathrm{C}$ for 12 to $72 \mathrm{~h}$.

\section{Total protein quantitation.}

Total protein concentration in protein extracts was determined, using Bio-Rad protein dye reagent according to the manufacturer's instructions. Optical density $(595 \mathrm{~nm})$ measurements were taken using a plate reader (450; Bio-Rad). Measurements were converted to protein concentration by comparison to BSA standards prepared in EB (discussed above).

\section{DNA bisulfite modification and sequencing.}

Bisulfite modification and sequencing was performed as described (Wang et al. 2001) with some modifications. Two sets of primers that amplified the same region of the V2:GUS $\Delta \mathrm{C}$ transgene were designed (Fig. 1G). One set was designed to bind to bisulfite-treated DNA unmethylated at $\mathrm{CpG}$ dinucleotides. The second set was designed to bind to bisulfite-treated DNA methylated at $\mathrm{CpG}$ dinucleotides. Forward and reverse primers from either primer set were used in various combinations. One primer combination was successfully used to amplify a product from bisulfite-treated DNA from V2:GUS $\Delta \mathrm{C}$ tissue, consisting of a forward primer to bind to DNA methylated at $\mathrm{CpG}$ dinucleotides and a reverse primer to bind to DNA unmethylated at $\mathrm{CpG}$ dinucleotides. The successful primers used were TLCV forward 5'TTTTTTACGTGATTGATGTGATCTGTCGAC-3' (TLCV nucleotide positions 39 to 68 ) and GUS reverse 5'-CATTAAAACTACCTAACACAACAATTACCCA-3' (GUS nucleotide positions 127 to 157). PCR products were purified using a Qiagen PCR purification kit. Plasmid DNA was prepared from $E$. coli using a Qiagen spin miniprep kit and was sequenced with T7 or SP6 primers. Tissue from multiple noninfected or TLCVinfected and silenced V2:GUS $\Delta \mathrm{C}$ plants was pooled, and total DNA was extracted as described for RNA extraction, with the addition of a RNase digestion step.

\section{ACKNOWLEDGMENTS}

We thank J. Stonor for technical assistance, V. Wesley for help with bisulfite sequencing, and J. Finnegan, P. Waterhouse, and V. Chandler for discussions. M. S. is supported by an Australian Postgraduate Award and a CSIRO supplementary scholarship.

\section{LITERATURE CITED}

Al-Kaff, N. S., Covey, S. N., Kreike, M. M., Page, A. M., Pinder, R., and Dale, P. . 1998. Transcriptional and posttranscriptional plant gene silencing in response to a pathogen. Science 279:2113-5.

Al-Kaff, N. S., Kreike, M. M., Covey, S. N., Pitcher, R., Page, A. M., and Dale, P. J. 2000. Plants rendered herbicide-susceptible by Cauliflower mosaic virus-elicited suppression of a $35 \mathrm{~S}$ promoter-regulated transgene. Nature Biotech. 18:995-999.

Behjatnia, S. A. A., Dry, I. B., Krake, L. R., Conde, B. D., Connelly, M I., Randles, J. W., and Rezaian, M. A. 1996. New potato spindle tuber viroid and tomato leaf curl geminivirus strains from a wild Solanum sp. Phytopathology 86:880-886.

Benjamin, D., and Jost, J.-P. 2001. Reversal of methylation-mediated repression with short-chain fatty acids: Evidence for an additional mechanism to histone deacetylation. Nucleic Acids Res. 2917:36033610 .

Chen, W. Y., Bailey, E. C., McCune, S. L., Dong, J.-Y., and Townes, T. M. 1997. Reactivation of silenced, virally transduced genes by inhibitors of histone deacetylase Proc. Natl. Acad. Sci. U.S.A. 94:57985803

Chen, W. Y., and Townes, T. M. 2000. Molecular mechanism for silencing virally transduced genes involves histone deacetylation of chromatin condensation. Proc. Natl. Acad. Sci. U.S.A. 97:377-382.

Chen, Z. J., and Pikaard, C. S. 1997. Epigenetic silencing of RNA polymerase I transcription: A role for DNA methylation and histone modification in nucleolar dominance. Genes Dev. 11:2124-2136.

Dry, I., Krake, L., Mullineaux, P., and Rezaian, A. 2000. Regulation of tomato leaf curl viral gene expression in host tissues. Mol. PlantMicrobe Interact. 13:529-537.

Dry, I. B., Krake, L. R., Rigden, J. E., and Rezaian, M. A. 1997. A novel subviral agent associated with a geminivirus: The first report of a DNA satellite. Proc. Natl. Acad. Sci. U.S.A. 94:7088-7093.

Dry, I. B., Rigden, J. E., Krake, L. R., Mullineaux, P. M., and Rezaian, M. A. 1993. Nucleotide sequence and genome organization of tomato leaf curl geminivirus. J. Gen. Virol. 74:147-151.

Finnegan, E. J., and Kovac, K. A. 2000. Plant DNA methyltransferases. Plant Mol. Biol. 43:189-201.

Francki, R. I. B., Milne, R. G., and Hatta, T. 1985. Atlas of Plant Viruses, vol. 1, p.33. CRC Press, Boca Raton, FL, U.S.A.

Fulnecek, J., Matysek, R., Kovarik, A., and Bezdek, M. 1998. Mapping of 5-methylcytosine residues in Nicotiana tabacum 5S rRNA genes by genomic sequencing. Mol. Gen. Genetics 259:133-141.

Hamilton, A., Voinnet, O., Chappell, L., and Baulcombe, D. 2002. Two classes of short interfering RNA in RNA silencing. The EMBO (Eur. Mol. Biol. Organ.) J. 21:4671-4679

Hanley-Bowdoin, L., Settlage, S. B., Orozco, B. M., Nagar, S., and Robertson, D. 1999. Geminiviruses: Models for plant DNA replication, transcription, and cell cycle regulation. Crit. Rev. Plant Sci. 18:71-106.

Jefferson, R. A., Burgess, S. M., and Hirsch, D. 1986. beta-Glucuronidase from Escherichia coli as a gene-fusion marker. Proc. Natl. Acad. Sci. U.S.A. 83:8447-8451.

Jenuwein, T., and Allis, C. D. 2001. Translating the histone code. Science 293:1074-1080.

Jeske, H., Lutgemeier, M., and Werner, P. 2001. DNA forms indicate rolling circle and recombination-dependent replication of Abutilon mosaic virus. The EMBO (Eur. Mol. Biol. Organ.) J. 20:6158-6167.

Jones, L., Hamilton, A. J., Voinnet, O., Thomas, C. L., Maule, A. J., and Baulcombe, D. C. 1999. RNA-DNA interactions and DNA methylation in post-transcriptional gene silencing. Plant Cell 11:2291-2301.

Jones, L., Ratcliff, F., and Baulcombe, D. C. 2001. RNA-directed transcriptional gene silencing in plants can be inherited independently of the RNA trigger and requires Met1 for maintenance. Current Biol. 11:747-757.

Kruh, J. 1982. Effects of sodium butyrate, a new pharmacological agent, on cells in culture. Mol. Cel. Biochem. 42:65-82.

Kumpatla, S. P., Teng, W., Buchholz, W. G., and Hall, T. C. 1997. Epigenetic transcriptional silencing and 5-azacytidine-mediated reactivation of a complex transgene in rice. Plant Phys. 115:361-73.

Lorincz, M. C., Schubeler, D., and Groudine, M. 2001. Methylationmediated proviral silencing is associated with $\mathrm{MeCP} 2$ recruitment and localised histone H3 deacetylation. Mol. Cel. Biol. 21:79137922

Lusser, A., Kolle, D., and Loidl, P. 2001. Histone acetylation: Lessons from the plant kingdom. Trends Plant Sci. 6:59-65.

Matzke, M. A., and Matzke, A. J. 1991. Differential inactivation and methylation of a transgene in plants by two suppressor loci containing homologous sequences. Plant Mol. Biol. 16:821-30. 
Mette, M. F., Aufsatz, W., van Der Winden, J., Matzke, M. A., and Matzke, A. J. 2000. Transcriptional silencing and promoter methylation triggered by double-stranded RNA. EMBO (Eur. Mol. Biol. Organ.) J. 19:5194-201.

Pikaart, M. J., Recillas-Targa, F., and Felsenfeld, G. 1998. Loss of transcriptional activity of a transgene is accompanied by DNA methylation and histone deacetylation and is prevented by insulators. Genes Dev. $12: 2852-2862$.

Pilartz, M., and Jeske, H. 1992. Abutilon mosaic virus double-stranded DNA is packed into minichromosomes. Virology 189:800-802.
Ratcliff, F. G., MacFarlane, S. A., and Baulcombe, D. C. 1999. Gene silencing without DNA: RNA-mediated cross-protection between viruses. Plant Cell 11:1207-1215.

Rigden, J. E., Dry, I. B., Krake, L. R., and Rezaian, M. A. 1996. Plant virus DNA replication processes in Agrobacterium: Insight into the origin of geminiviruses? Proc. Natl. Acad. Sci. U.S.A. 93:1028010284.

Wang, M.-B., Wesley, V., Finnegan, J. E., Smith, N. A., and Waterhouse, P. M. 2001. Replicating satellite RNA induces sequence-specific DNA methylation and truncated transcripts in plants. RNA 7:16-28. 